\title{
Avaliação dos riscos psicossociais no ambiente de trabalho: Contribuições para a saúde do servidor público federal
}

\author{
Evaluation of psychosocial risks in the workplace: Contributions to the health of federal public \\ servants \\ Evaluación de riesgos psicosociales en el ambiente de trabajo: Contribuciones a la salud del \\ empleado público federal
}

Recebido: 07/06/2021 | Revisado: 15/06/2021 | Aceito: 17/06/2021 | Publicado: 02/07/2021

Ana Paula da Fonseca da Costa Fernandes
ORCID: https://orcid.org/0000-0002-2256-9017
Instituto Federal de Educação, Ciência e Tecnologia do Rio de Janeiro, Brasil
E-mail: anapaula.fonseca@live.com
Joanir Pereira Passos
ORCID: https://orcid.org/0000-0002-6880-4545
Universidade Federal do Estado do Rio de Janeiro, Brasil
E-mail: joppassos@ @otmail.com

\begin{abstract}
Resumo
O estudo tem por objetivo mapear os riscos psicossociais a que servidores públicos federais, em uma instituição de ensino estão expostos e construir, em conjunto com os trabalhadores, estratégias para o enfrentamento dos riscos psicossociais relacionados ao trabalho. Trata-se de estudo quanti-qualitativo, avaliativo, em amostra de 97 servidores de uma instituição de ensino. Verificou-se risco moderado para organização prescrita do trabalho, sendo espaço físico o agente de maior risco psicossocial; a predominância do estilo gerencialista torna-se fator de risco, enquanto desorganização do ambiente com mudanças, oportunidades desiguais de ascensão e tolerância ao individualismo foram agentes de alto risco psicossocial. Quanto ao sofrimento e adoecimento dos servidores, foi verificado risco moderado para esgotamento mental e desenvolvimento de danos físicos relacionados ao trabalho. Foram identificadas estratégias defensivas, devendo ser estimuladas as que auxiliam na resolução da causa do sofrimento e as estratégias indiretas, que auxiliam na eliminação da energia pulsional. Sugestões de investimentos emergiram da fala dos servidores, como capacitação, mudança na cultura organizacional, mapeamento de processos e competências, investimentos em infraestrutura e comunicação. Torna-se fundamental estender esta análise para as demais unidades da instituição, realizando análise global dos riscos psicossociais, contribuindo para a promoção da saúde mental dos trabalhadores.
\end{abstract}

Palavras-chave: Saúde do trabalhador; Riscos ocupacionais; Saúde mental; Ambiente de trabalho.

\begin{abstract}
The study aims to map the psychosocial risks to which federal civil servants in an educational institution are exposed and to build, together with workers, strategies for coping with psychosocial risks related to work. This is a quantitative-qualitative, evaluative study, in a sample of 97 civil servants from an educational institution. There was a moderate risk for prescribed work organization, with physical space being the agent with the highest psychosocial risk; the predominance of the managerial style becomes a risk factor, while disorganization of the environment with changes, unequal opportunities for growth and tolerance to individualism were agents of high psychosocial risk. As for the suffering and illness of the employees, there was a moderate risk for mental exhaustion and the development of work-related physical damage. Defensive strategies were identified, and those that help solve the cause of suffering and indirect strategies that help eliminate drive energy should be encouraged. Investment suggestions emerged from the employees' speech, such as training, change in organizational culture, mapping of processes and competencies, investments in infrastructure and communication. It is essential to extend this analysis to the other units of the institution, carrying out a global analysis of psychosocial risks, contributing to the promotion of workers' mental health.
\end{abstract}

Keywords: Occupational health, Occupational risks; Mental health; Working environment.

\section{Resumen}

El estudio tiene como objetivo mapear los riesgos psicosociales a los que están expuestos los funcionarios federales de una institución educativa y construir, junto con los trabajadores, estrategias para hacer frente a los riesgos psicosociales relacionados con el trabajo. Se trata de un estudio cuantitativo-cualitativo, evaluativo, en una muestra de 
97 funcionarios de una institución educativa. Existía un riesgo moderado para la organización del trabajo prescrita, siendo el espacio físico el agente de mayor riesgo psicosocial; el predominio del estilo gerencial se convierte en factor de riesgo, mientras que la desorganización del entorno con cambios, la desigualdad de oportunidades de crecimiento y la tolerancia al individualismo fueron agentes de alto riesgo psicosocial. En cuanto al sufrimiento y enfermedad de los empleados, existía un riesgo moderado de agotamiento mental y desarrollo de daño físico relacionado con el trabajo. Se identificaron estrategias defensivas y se deben fomentar aquellas que ayuden a resolver la causa del sufrimiento y las estrategias indirectas que ayuden a eliminar la energía impulsora. Las sugerencias de inversión surgieron del discurso de los empleados, como capacitación, cambio en la cultura organizacional, mapeo de procesos y competencias, inversiones en infraestructura y comunicación. Es fundamental extender este análisis al resto de unidades de la institución, realizando un análisis global de riesgos psicosociales, contribuyendo a la promoción de la salud mental de los trabajadores.

Palabras clave: Salud del trabajador; Riesgos laborales; Salud mental; Ambiente de trabajo.

\section{Introdução}

O trabalho possui papel fundamental na vida do indivíduo, pois garante a subsistência, além de permitir a socialização e ser fonte de satisfação pessoal, contribuindo assim, para dar sentido à vida. Porém, o ambiente de trabalho pode ser fonte de exposição a riscos ocupacionais, dentre eles, os riscos psicossociais. A necessidade de preservação da saúde dos trabalhadores perpassa a garantia da manutenção da mão-de-obra para o trabalho e alcança, nos dias atuais, a discussão acerca do cuidado holístico, entendendo as subjetividades que permeiam a relação saúde-doença-trabalho.

Quanto aos riscos psicossociais, a subjetividade que envolve a sua interação com o trabalhador, os tornam de difícil conceituação, embora a Organização Internacional do Trabalho - OIT (2018, p. 17) os tenha denominado como violência estrutural, uma vez que as características estruturais e organizativas do trabalho podem afetar "a dignidade, a segurança, a saúde e o bem-estar da vítima". A European Agency for Safety and Health at Work - EU-OSHA define os riscos psicossociais como "o risco que pode comprometer o bem-estar psicológico ou físico do trabalhador decorrente da interação entre a concepção e gestão do trabalho, no contexto organizacional e social” (Cox; Griffiths, 2005 apud EU-OSHA, 2014, p. 5).

No que tange ao serviço público, as ações em saúde mental tendem a se restringir a perícias médicas; e a promoção de saúde tende a sofrer influência do perfil de adoecimento dos trabalhadores. Assim, estas ações não conseguem responder a demandas específicas e particulares de cada ambiente laboral. Além disso, as transformações no âmbito do trabalho podem ser vistas também no serviço público, sendo verificada a flexibilização das relações trabalhistas caminhando em conjunto com a precarização (Pereira, 2018).

O isolamento das pessoas proveniente das transformações do mundo laboral, em especial promovido pela pluralização de diferentes tipos de contratos trabalhistas, foi observado como principal fonte de adoecimento mental relacionado ao trabalho (Merlo, Bottega \& Perez, 2015). Além disso, a solidão enfraquece, consequentemente, a solidariedade e as formas dos trabalhadores de lidarem com o sofrimento de maneira coletiva (Antunes \& Praun, 2015).

A exposição a riscos psicossociais pode desencadear não somente transtornos de ordem psíquica, mas também podem ocorrer desdobramentos de ordem física que possuem sua gênese no adoecimento mental prévio (Dejours, Abdoucheli \& Jayet, 1994; Gaulejac, 2007; Neffa, 2015). Para Seligmann-Silva (2011), por sua complexidade, os transtornos psíquicos são de difícil diagnóstico diferencial, em especial os que tem relação com o trabalho.

No entanto, seu potencial efeito danoso para os trabalhadores, os riscos psicossociais configuram entrave para busca de qualidade de vida no trabalho, em especial, de servidores públicos federais, uma vez que não há legislações norteadoras para implementação de ações de caráter obrigatório que avalie os ambientes e relações de trabalho para tal risco. Deste modo, o objeto de investigação do presente estudo foi os riscos psicossociais no ambiente de trabalho e como objetivos: mapear os riscos psicossociais a que os servidores públicos federais em uma instituição de ensino estão expostos; construir, em conjunto com os trabalhadores, estratégias para o enfrentamento dos riscos psicossociais relacionados ao trabalho. 


\section{Metodologia}

Trata-se de recorte de tese de doutorado, cujo estudo avaliativo, transversal, de natureza quanti-qualitativa permitiu o mapeamento e o enfrentamento dos riscos psicossociais no ambiente de trabalho por meio da aplicação do questionário proposto por Facas (2013), denominado Protocolo de Avaliação dos Riscos Psicossociais no Trabalho - PROART. Do total de 193 servidores lotados no campus onde ocorreu a análise, foram obtidas 127 respostas. A amostra, no entanto, foi composta por 97 servidores que preencheram o questionário em sua totalidade.

Para desenvolvimento do estudo foi escolhida uma instituição pública federal de ensino, situada no estado do Rio de Janeiro, com estrutura pluridisciplinar e multicampi, cuja relação de trabalho é estabelecida por meio do Regime Jurídico Único instituído pela Lei $\mathrm{n}^{\circ} 8.112 / 1990$, sendo os trabalhadores, portanto, servidores públicos, contratados por meio de concurso público. A escolha da instituição se deu pela recente implantação dos exames periódicos em saúde.

O PROART está organizado em quatro escalas, contabilizando 92 afirmativas cuja possibilidade de resposta segue a escala de frequência Likert, variando entre os pontos 1 que significa <nunca> e 5 que significa <sempre>. Por meio dele, é possível avaliar a organização prescrita do trabalho, que conta com a divisão de tarefas e a divisão social do trabalho; os estilos de gestão; o sofrimento patogênico no trabalho, evidenciado pela falta de sentido no trabalho, esgotamento mental e falta de reconhecimento; e os danos físicos, sociais e psicológicos.

A coleta de dados foi feita por meio de aplicação do PROART eletrônico enviado por e-mail ao longo do mês de setembro de 2018, após sensibilização dos servidores de maneira coletiva e presencial, onde foram informados os objetivos do estudo e resultados esperados. Apesar de não ser necessária a identificação dos respondentes, foi solicitada a indicação do setor de lotação, para que as intervenções no ambiente de trabalho sejam efetivas. As respostas foram arquivadas em plataforma institucional, de maneira eletrônica.

Os dados foram tratados de maneira coletiva, sem possibilidade de identificação. O tratamento estatístico foi feito mediante utilização do programa estatístico $\mathrm{R}$ ( $\mathrm{R}$ version 3.4.4, 2018). Os testes estatísticos foram aplicados após a verificação prévia da normalidade da distribuição da amostra. Deste modo, foram consideradas na análise descritiva, a média aritmética, a mediana, o desvio-padrão e a distribuição da frequência, além dos testes paramétricos de análise da variância de um padrão (ANOVA) e teste t, e testes não paramétricos Wilcoxon, Qui-quadrado, Kruskal-Wallis para verificar a influência de diversas fontes de variação entre os grupos do perfil demográfico, cujo nível de significância considerado foi menor que 0,05 .

Os dados qualitativos do PROART foram compostos por perguntas abertas constantes no protocolo, cujas respostas foram transcritas literalmente, por meio do Microsoft Office Word 2007 sendo salvas no formato <.doc>. Para análise foi utilizada a análise de conteúdo proposta por Bardin (2010), utilizando como recorte o tema para viabilizar a análise dos dados. Conforme sugerido por Bardin (2010), a análise seguiu sua organização por meio de polos cronológicos.

Os resultados receberam tratamento estatístico por meio da contabilização dos temas por frequência simples e compuseram um quadro onde foram registrados os temas mais relevantes e respectivas frequências absoluta e relativa. A categorização foi feita mediante agrupamento de temas de acordo com sua semântica.

Por envolver utilização de banco de dados sem possibilidade de identificação de participantes, não houve necessidade de aplicação de Termo de Consentimento Livre e Esclarecido, conforme estabelecido pela Resolução CNS nº 466/2012. O estudo foi submetido ao Comitê de Ética em Pesquisa da UNIRIO, aprovado sob o número 3.209.003 e ao Comitê de Ética em Pesquisa da Instituição sob o número 3.331.403, ambos em maio de 2019. Ressalta-se o caráter não obrigatório da participação. Os valores éticos, morais, religiosos, culturais, bem como os hábitos e os costumes dos participantes foram respeitados em todas as etapas do estudo. 


\section{Resultados}

A partir dos registros institucionais de afastamentos de servidores, de 2013 a 2017 os transtornos mentais e comportamentais foram os que mais afastaram os servidores públicos federais desta instituição e por maior tempo, caracterizado pelo total de dias não trabalhados. Apesar destes dados serem importantes para identificação de doença mental, não é possível, porém, verificar se tais adoecimentos possuem relação com o trabalho ou foram potencializados pela exposição ocupacional aos riscos psicossociais. Tais dados reforçam a necessidade de implantação de metodologia que possibilite a avaliação ambiental quanto aos referidos riscos.

Quanto ao perfil sociodemográfico, houve predominância do sexo feminino $(55,6 \%)$ e da faixa etária de adultos jovens entre 30 e 39 anos (49,3\%), com tempo de serviço médio na instituição de 4,6 anos (69,2\%). Quanto à escolaridade, a pós-graduação se mostrou predominante (66,7\%), sendo a maioria técnicos administrativos de nível superior (50\%). Cabe ressaltar que não há possibilidade de ascensão de nível do médio (D) ao superior (E), mesmo para servidores que concluíram ensino superior. No entanto, por se tratar de instituição de ensino com incentivo ao aprimoramento profissional, é possível que os servidores se sintam estimulados a concluir sua formação acadêmica.

Para avaliar a influência do perfil sociodemográfico nas dimensões avaliadas, os dados foram distribuídos em oito grupos, a saber: idade, sexo, escolaridade, reside com, tempo de serviço, cargo com gratificação, vínculo, problemas de saúde. Para o grupo vínculo foram considerados nível C (fundamental), nível D (médio) e nível E (superior). Para o grupo problemas de saúde foi considerado não ter tido problemas, de 1 a 2 problemas e 3 ou mais problemas de saúde relacionados ao trabalho.

Quanto à organização prescrita do trabalho, que avalia a percepção dos respondentes acerca da forma como o trabalho se organiza, considerando condições para a execução das tarefas, autonomia, variabilidade e flexibilidade de prazos, foi observado risco moderado para riscos psicossociais. O espaço físico disponível para a realização do trabalho se mostrou inadequado, sendo o item de alto risco psicossocial. A flexibilidade de prazos e a variabilidade de tarefas se mostraram de baixo risco psicossocial.

Após aplicação da análise de variância ANOVA e do teste t (admitindo p<0,05), observou-se significância para os grupos sociodemográficos <vínculo> e <problemas de saúde> tanto para a divisão das tarefas quanto para a divisão social do trabalho (Tabela 1). Deste modo, foi feita a distribuição das médias e do desvio-padrão para estes grupos, que indicou maior risco para servidores de nível não superior e aumento dos problemas de saúde relacionados ao trabalho à medida que houve aumento da exposição aos riscos psicossociais relacionados à organização prescrita do trabalho. O teste de Tukey, no entanto, não rejeitou a hipótese de igualdade entre as médias " 1 ou 2 problemas de saúde" e "3 ou mais problemas de saúde".

Tabela 1 - Tratamento estatístico para as dimensões divisão das tarefas e divisão social do trabalho.

\begin{tabular}{lccc}
\hline \multicolumn{1}{c}{ GRUPOS } & TESTE & $\begin{array}{c}\text { DIVISÃO DAS } \\
\text { TAREFAS } \\
\text { p-valor }\end{array}$ & $\begin{array}{c}\text { DIVISÃO SOCIAL DO } \\
\text { TRABALHO } \\
\text { p-valor }\end{array}$ \\
\hline Idade & ANOVA F-test & 0,41 & 0.816 \\
Sexo & t-test & 0,718 & 0.619 \\
Escolaridade & ANOVA F-test & 0,125 & 0.502 \\
Reside com & ANOVA F-test & 0,936 & 0.307 \\
Tempo de serviço campus & ANOVA F-test & 0,453 & 0.928 \\
Cargo com gratificação & ANOVA F-test & 0,548 & 0.379 \\
Vínculo & t-test & 0,009 & 0.017 \\
Problemas de saúde & ANOVA F-test & $<0,001$ & $<0.001$ \\
\hline
\end{tabular}

Fonte: Autores. 
A escala de estilo de gestão, que avalia as características praticadas pela gestão, de acordo com a percepção dos respondentes, verificou presença moderada do estilo gerencialista, em comparação com o estilo coletivista. A desorganização do ambiente com mudanças foi verificada como característica do estilo gerencialista. A falta de oportunidades semelhantes de ascensão profissional e a tolerância ao individualismo reforçam a predominância do estilo gerencialista. O planejamento não rigoroso das ações e o não incentivo à idolatria dos chefes, no entanto, foram fatores que se mostraram positivos, aproximando-se do estilo coletivista de gestão.

Os grupos <vínculo> e <problemas de saúde> se mostraram significativos, após aplicação do teste de variância ANOVA e teste t para ambos os estilos de gestão. As médias para ambos os grupos variaram dentro do risco moderado na presença do estilo gerencialista de gestão, que diz respeito a uma gestão mais normativa, burocrática e engessada. O teste de Tukey não rejeitou a hipótese de igualdade entre as médias de respostas do grupo <problemas de saúde>. Para o estilo coletivista, que preza pela união, coletividade e diálogo, verificou-se risco aumentado para vínculo não superior e aumento dos problemas de saúde à medida que diminui o predomínio deste estilo. $\mathrm{O}$ teste de Tukey não rejeitou a hipótese de igualdade entre "1 ou 2 problemas de saúde" e " 3 ou mais problemas de saúde". As análises estatísticas estão descritas na Tabela 2.

Tabela 2 - Tratamento estatístico para as dimensões estilo gerencialista e estilo coletivista.

\begin{tabular}{lccc}
\hline \multicolumn{1}{c}{ GRUPOS } & TESTE & $\begin{array}{c}\text { ESTILO } \\
\text { GERENCIALISTA } \\
\text { p-valor }\end{array}$ & $\begin{array}{c}\text { ESTILO } \\
\text { COLETIVISTA } \\
\text { p-valor }\end{array}$ \\
\hline Idade & ANOVA F-test & 0.793 & 0.758 \\
Sexo & t-test & 0.181 & 0.139 \\
Escolaridade & ANOVA F-test & 0.551 & 0.573 \\
Reside com & ANOVA F-test & 0.279 & 0.754 \\
Tempo de serviço campus & ANOVA F-test & 0.908 & 0.949 \\
Cargo com gratificação & ANOVA F-test & 0.288 & 0.618 \\
Vínculo & t-test & 0.005 & 0.036 \\
Problemas de saúde & ANOVA F-test & 0.01 & $<0.001$ \\
\hline
\end{tabular}

Fonte: Autores.

A escala de sofrimento patogênico no trabalho os sentimentos dos respondentes em relação ao seu trabalho e está dividida em três dimensões: falta de sentido no trabalho, que aborda o sentimento de inutilidade no trabalho e a percepção de ausência de significado do trabalho; esgotamento mental, que aborda o desgaste e o desânimo em relação ao trabalho; falta de reconhecimento, que aborda o sentimento de desvalorização do serviço prestado e falta de espaço para autonomia e criatividade. As análises estatísticas estão descritas na Tabela 3.

A dimensão esgotamento mental indicou risco moderado para riscos psicossociais, estando as demais indicadas como baixo risco psicossocial. A falta de motivação para realizar as tarefas indicaram médio risco na dimensão falta de sentido no trabalho. A desvalorização do trabalho pela instituição, a revolta com a submissão da chefia a ordens superiores e a falta de liberdade para dizer o que pensa sobre o trabalho encontraram-se dentro do médio risco psicossocial na dimensão falta de reconhecimento. $\mathrm{O}$ apoio dos colegas de trabalho e a convivência com eles se mostraram fatores positivos.

Após aplicação de testes paramétricos e não paramétricos foi possível verificar significância para os grupos

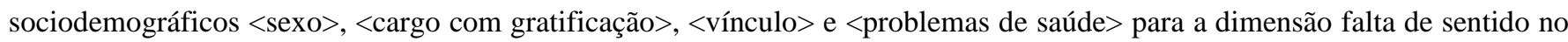
trabalho; e para os grupos <vínculo> e <problemas de saúde> para as dimensões esgotamento mental e falta de reconhecimento. 
Tabela 3 - Tratamento estatístico para as dimensões falta de sentido no trabalho, esgotamento mental e falta de reconhecimento.

\begin{tabular}{|c|c|c|c|c|c|c|}
\hline \multirow[t]{2}{*}{ GRUPOS } & \multicolumn{2}{|c|}{$\begin{array}{c}\text { FALTA DE SENTIDO } \\
\text { NO TRABALHO }\end{array}$} & \multicolumn{2}{|c|}{$\begin{array}{c}\text { ESGOTAMENTO } \\
\text { MENTAL }\end{array}$} & \multicolumn{2}{|c|}{$\begin{array}{c}\text { FALTA DE } \\
\text { RECONHECIMENTO }\end{array}$} \\
\hline & TESTE & p-valor & TESTE & p-valor & TESTE & p-valor \\
\hline Idade & ANOVA F-test & 0.061 & ANOVA F-test & 0.132 & Kruskal-Wallis & 0.669 \\
\hline Sexo & t-test & 0.042 & t-test & 0.34 & Wilcoxon & 0.458 \\
\hline Escolaridade & Kruskal-Wallis & 0.384 & ANOVA F-test & 0.7 & Kruskal-Wallis & 0.622 \\
\hline Reside com & ANOVA F-test & 0.128 & ANOVA F-test & 0.679 & ANOVA F-test & 0.145 \\
\hline Tempo de serviço campus & ANOVA F-test & 0.239 & ANOVA F-test & 0.365 & Kruskal-Wallis & 0.451 \\
\hline Cargo com gratificação & ANOVA F-test & 0.023 & ANOVA F-test & 0.892 & Kruskal-Wallis & 0.401 \\
\hline Vínculo & Wilcoxon test & 0.049 & t-test & 0.01 & Wilcoxon & 0.033 \\
\hline Problemas de saúde & Kruskal-Wallis & $<0.001$ & ANOVA F-test & $<0.001$ & $\begin{array}{l}\text { Kruskal- } \\
\text { Wallis }\end{array}$ & $<0.001$ \\
\hline
\end{tabular}

Fonte: Autores.

Após a distribuição das médias e desvios-padrão para dimensão falta de sentido no trabalho, observou-se que o sexo feminino e a presença de cargo com gratificação apresentaram médias indicando baixo risco psicossocial, podendo ser fatores positivos. O teste de Tukey, no entanto, não rejeitou a hipótese de igualdade entre presença ou não de cargo com gratificação. O vínculo superior se mostrou com médias inferiores em relação ao vínculo não superior nas três dimensões, embora não tenha sido verificada diferença significativa para a dimensão falta de sentido no trabalho. Os problemas de saúde aumentaram à medida que aumentou a falta de sentido para o trabalho. O teste de Tukey não rejeitou a hipótese entre " 1 ou 2 problemas de saúde" e "3 ou mais problemas de saúde" para as três dimensões.

Quanto aos danos físicos e psicossociais no trabalho, a escala aborda os danos psicológicos, com sentimentos negativos em relação a si e aos outros; os danos sociais, que indicam dificuldade de interação social; e os danos físicos, que abordam os problemas de saúde que possam ser associados com o trabalho. Foi verificado baixo risco para a dimensão danos sociais, o que corrobora o achado anterior em que a interação com colegas de trabalho se mostrou positiva. Os danos psicológicos e físicos encontraram-se dentro do médio risco psicossocial. Foram observados como médio risco para danos psicológicos o mal humor, a vontade de desistir de tudo e a tristeza.

Quanto ao perfil sociodemográfico, os testes paramétricos e não paramétricos indicaram significância para os grupos <vínculo> e <problemas de saúde> para danos psicológicos e para o grupo <problemas de saúde> para danos físicos e para os danos sociais. O vínculo superior se mostrou baixo risco para danos físicos enquanto houve aumento proporcional dos problemas de saúde à medida que aumentou o risco para danos físicos e psicológicos. Os problemas de saúde indicaram médio risco a partir de "3 ou mais" para os danos sociais. O teste de Tukey não rejeitou a hipótese de igualdade entre as médias de "1 ou 2" e "3 ou mais" para os danos psicológicos, entre as médias "nenhum", "1 ou 2" e "3 ou mais" para danos físicos e rejeitou a hipótese de igualdade dos problemas de saúde para danos sociais.

O teste de correlação de Spearman (Figura 1), aplicado em todas as escalas do PROART, verificou que a dimensão divisão social do trabalho possui forte correlação com a dimensão estilo coletivista (rho=0,73) e com a dimensão falta de reconhecimento (rho $=-0,76)$. A dimensão danos sociais possui forte correlação com as dimensões danos físicos $($ rho $=0,74)$ e danos psicológicos $(\mathrm{rho}=0,86)$. A dimensão esgotamento mental possui forte correlação com as dimensões danos psicológicos $($ rho $=0,71)$ e falta de sentido no trabalho $(\mathrm{rho}=0,73)$.

Também foi verificada correlação entre as dimensões divisão social do trabalho com as dimensões estilo gerencialista 
$(\mathrm{rho}=-0,68)$ e falta de sentido no trabalho $(\mathrm{rho}=-0,68)$. A dimensão estilo gerencialista também possui correlação com a dimensão falta de reconhecimento $(r h o=0,66)$. A dimensão esgotamento mental possui correlação com as dimensões falta de reconhecimento $(\mathrm{rho}=0,68)$ e danos sociais $(\mathrm{rho}=0,65)$.

Figura 1 - Correlação entre as dimensões do PROART.

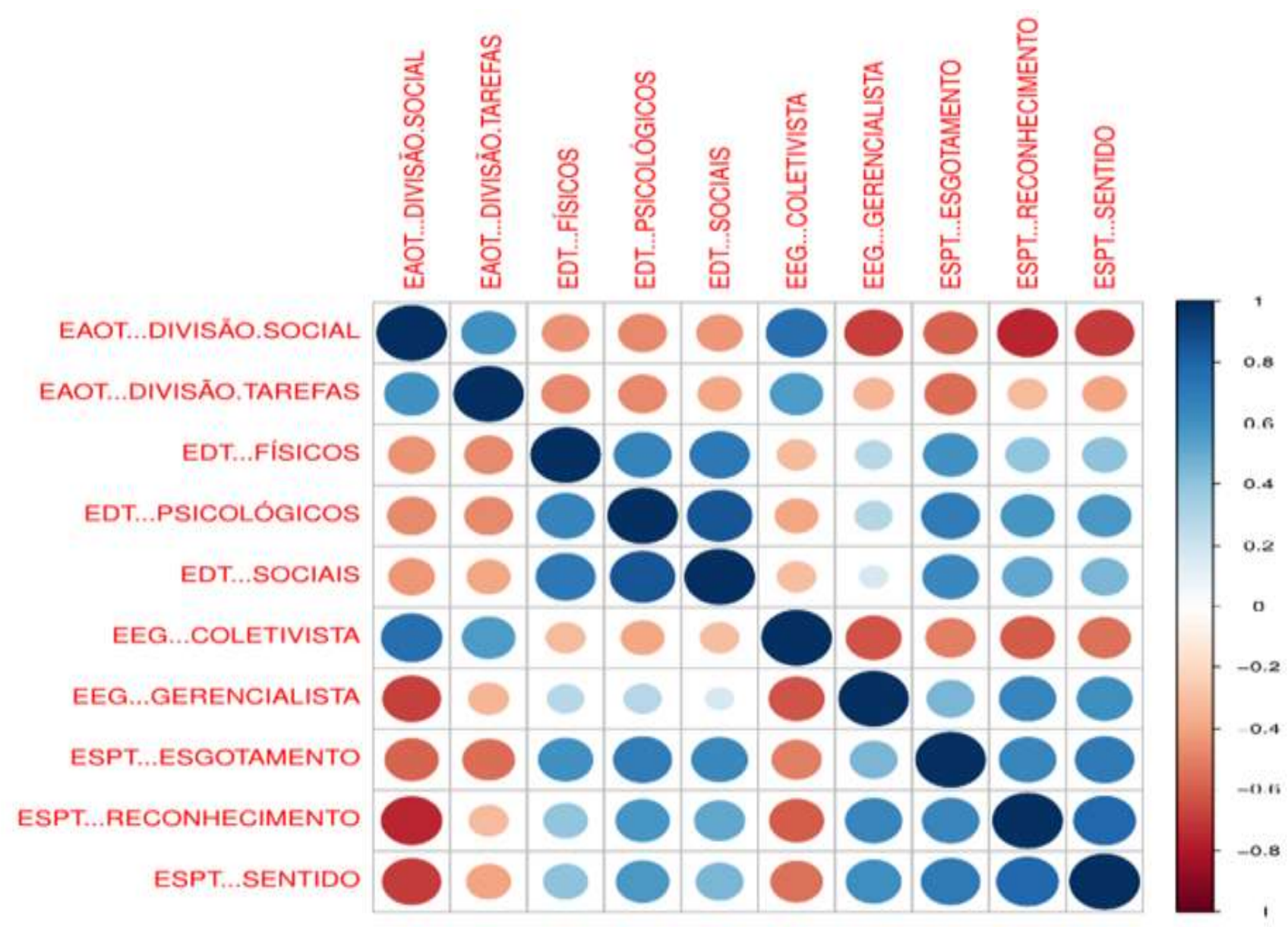

Fonte: Autores.

Acerca dos dados qualitativos, foram construídas quatro categorias temáticas: gestão, ambiente e organização do trabalho; repercussões do trabalho na saúde do trabalhador; estratégias de defesa contra os riscos psicossociais; sugestões de investimento para enfrentamento dos riscos psicossociais. A primeira categoria abordou os problemas identificados pelos servidores enquanto risco psicossocial. O tema mais frequente foi o mapeamento de processos e de competências (15,8\%), seguido do desprezo pelo saber da equipe $(9,5 \%)$, condicionantes estruturais $(4,5 \%)$, cultura organizacional $(5,9 \%)$ e relações de trabalho $(9 \%)$.

A segunda categoria apontou sentimentos negativos $(7,7 \%)$ e positivos $(2,7 \%)$ dos servidores em relação ao trabalho e condições de saúde $(2,3 \%)$ que tiveram como gênese o trabalho. A terceira categoria identificou o não enfrentamento (10,9\%) da situação causadora de sofrimento, estratégias indiretas $(7,3 \%)$ e enfrentamento direto (4,5\%). A quarta categoria abordou melhorias $(10,8 \%)$ necessárias ao ambiente de trabalho, diálogo $(5,4 \%)$ e a necessidade de capacitação $(4,1 \%)$ dos gestores, dos setores e necessidade de treinamentos na instituição. 


\section{Discussão}

A Categoria 1: gestão, ambiente e organização do trabalho, aponta como alto risco psicossocial o número insuficiente de servidores e de recursos para execução das tarefas, além da injustiça na distribuição de tarefas, baixa participação dos servidores no processo decisório, informações pouco claras sobre a execução das tarefas e falta de flexibilidade de normas. Estes apontamentos revelam problemas relacionados ao mapeamento de processo e de competências, conforme ilustrado na fala, a seguir:

Não exerço a função para qual passei no concurso e não estou no setor que gostaria, não tenho confiança na chefia (S46).

Para Slack, Chambers e Johnston (2009) mapear processos significa descrever como as atividades se relacionam dentro do processo, permitindo aprimorá-lo. De acordo com a Association of Business Process Management Professionals ABPMP International (2013) os benefícios da implantação do gerenciamento de processos engloba tanto a instituição, a gerência, quanto os profissionais e o público-alvo. Contudo, Dejours (2016) explica que é preciso cautela no uso de ferramentas de organização e de gestão para que não afete de maneira negativa a saúde mental dos trabalhadores.

Outro ponto identificado como alto risco psicossocial foi a inadequação do espaço físico, englobando falta de material e manutenção de patrimônio. Problemas como ruído, baixa iluminação e disposição inadequada de mobiliário, além de risco de acidentes também foram levantados pelos respondentes. Quanto a este aspecto, Neffa (2015) explica que os riscos provenientes das condições de trabalho podem agravar os riscos ambientais (físicos, químicos e biológicos) e que a heterogeneidade da exposição ocupacional contribui para agravar os impactos na saúde do trabalhador pela potencialização dos riscos. Para Dul e Weerdmeester (2012) as condições de conforto ambiental podem ser fontes geradoras de estresse e a sensação de insegurança e da possibilidade de acidentes geram medo.

Sobre o estilo de gestão, houve predomínio do estilo gerencialista, sendo pontuados os laços afetivos fracos, a valorização da hierarquia, o desprezo pelo saber da equipe, a falta da participação da equipe no processo decisório. Autores concordam que o trabalhador adquire saberes próprios do seu ofício, a partir da sua experiência profissional (Dejours, 2015; Neffa, 2015). Ao desapropriar este saber do trabalhador, o gestor também desapropria sua liberdade de invenção, tolhendo sua criatividade (Dejours, 2015). Além disso, o engessamento do trabalho, visto como intransigência e autoritarismo pelos servidores, tende a prejudicar a confiança, o convívio e a saúde dos trabalhadores, sendo fator de desgaste emocional e, consequente, facilitador de acidentes (Dejours, 2016; Rebouças et al., 1989).

A cultura organizacional que permite o descumprimento de regras institucionais ou sociais para obtenção de vantagem, reforçam os sentimentos negativos em relação ao trabalho e aos gestores. Para Neffa (2015) a cultura organizacional se torna um risco psicossocial quando vai de encontro com os valores e a ética profissional do indivíduo, podendo gerar sentimento de inutilidade e desprestígio. Siegrist (1996) reforça que o desequilíbrio entre o nível de esforço e a recompensa causa prejuízos para a saúde do trabalhador. Estes apontamentos são evidenciados nas falas a seguir:

A relação de trabalho, entre a chefia imediata e os subordinados gera insegurança, pela falta de planejamento (tudo é para ontem, sem que os subordinados tenhamos tempo de analisar e realizar os procedimentos com segurança), prioridades políticas ("puxa saquismos", inversão de prioridades diante da vontade do gestor). (S169) A questão principal é o ENORME esforço necessário para que as boas e corretas iniciativas sejam reconhecidas e integrem o plano do instituto. O que é correto não deveria ser tão difícil de ser implantado. (S184)

No entanto, os servidores ponderam que esta cultura organizacional pode ser resultado do despreparo das chefias, que são evidenciados pelas ações que não condizem com o processo de trabalho dos setores sob estas gestões. Neste aspecto, a 
ausência de oportunidade de ascensão para todos os servidores reforça que a escolha do servidor para o cargo de gestão nem sempre condiz com o conhecimento técnico necessário e/ou perfil de liderança. Para Dejours (2016) o gestor deve ser competente tecnicamente e possuir profundo conhecimento do trabalho vivo de seus subordinados. De maneira geral, os agentes de médio e alto risco psicossocial identificados na Escala de Organização Prescrita do Trabalho foram congruentes com os apontamentos das falas dos servidores.

A Categoria 2: repercussões do trabalho na saúde do trabalhador confirma a escala descrita anteriormente enquanto preditora das escalas de avaliação do sofrimento patogênico e dos danos físicos e psicossociais. Apesar de indicarem baixo risco em uma análise global, as falas dos servidores indicaram situações de sofrimento e de adoecimento em curso. Na Escala de Sofrimento Patogênico no Trabalho foi verificado médio risco para esgotamento mental.

O trabalho é visto como desgastante, desanimador, fonte de sobrecarga, revolta e insatisfação. Na Escala de Danos Físicos e Psicossociais, os danos físicos foram identificados como médio risco e as principais queixas foram dores nas costas, alterações do sono e dores no corpo. Sentimentos negativos e positivos estiveram presentes nas falas dos servidores, com predomínio dos negativos, conforme verificado, a seguir:

\section{(...) é o pior setor para se trabalhar. Quem é da [suprimido] não possui nenhuma qualidade de vida e o trabalho é uma tortura (S114). \\ Além disso, a insegurança da chefia imediata e a vontade em manter o cargo a qualquer custo, trouxe prejuízos nas relações de trabalho, fazendo com que o setor adoecesse e ficasse desmotivado. $O$ fato de sermos tolhidos de dialogar com a chefia superior a imediata, oprime (S169).}

De acordo com Dejours (2015), o trabalho robotizado, despersonalizado, em que o trabalhador é privado da sua criatividade gera sentimentos de indignidade, inutilidade e contribui para falta de significação do trabalho, levando também ao cansaço. Outros sentimentos negativos, como raiva, desmotivação e insegurança na chefia são frutos da falta de valorização do saber da equipe e de processos de trabalho mal definidos, além do despreparo técnico das chefias.

Também foram apontados problemas físicos e sintomas que os servidores associam ao estresse a que estão submetidos no trabalho, como picos de hipertensão arterial, dores de cabeça e pelo corpo e contratura muscular. Neffa (2015) ressalta a existência de enfermidades que podem surgir ou ser agravadas pelo estresse constante. Quanto aos danos sociais, foi verificada possível ação protetora da saúde proveniente do bom relacionamento com os colegas de trabalho. Além disso, os servidores também relataram manutenção da esperança e de sentimentos positivos em relação ao trabalho, o que, para Dejours (2015) pode significar que, nestes casos, os servidores conseguem descarregar suas energias pulsionais por meio da organização do trabalho.

A Categoria 3: estratégias de defesa contra os riscos psicossociais traz como principal estratégia o não enfrentamento, o que se torna prejudicial para a saúde do trabalhador por não ajudar nas descargas psíquicas produzidas pelo trabalho e, principalmente, por não ajudar a resolver o problema. Além disso, interfere na condição esforço-recompensa descrita por Siegrist (1996), uma vez que o indivíduo é forçado a entregar um trabalho que não condiz com suas aspirações profissionais, ferindo, assim, a sua necessidade de realização e identidade com o produto do seu trabalho, como se observa na fala, a seguir:

Refaço meu planejamento, mas não fica do jeito que gosto de trabalhar (S62).

Para Seligmann (2016), a coerção também bloqueia a criatividade agravando os prejuízos para a qualidade do trabalho. Merlo (2016) explica que o trabalhador, ao executar uma tarefa, deixa marcas, a sua contribuição e espera ser recompensado por isso. Deste modo, ele constrói sua identidade e se sente progredindo. De acordo com as falas dos servidores, 
as condicionantes estruturais, como falta de espaço, quantitativo de pessoal, também influenciam na forma como eles enxergam a qualidade do serviço prestado, pois se sentem impotentes diante deste problema, o que contribui para agravar a frustração.

Simplesmente aceito essa falta de espaço. Entrego um trabalho que está aquém da qualidade que posso atribuir a ele, somente para dar conta de prazos (S135).

O enfrentamento direto também foi descrito pelos servidores, como proatividade na resolução dos problemas e criação de ferramentas para embasar o trabalho em situações posteriores. A liberdade para criatividade estimula o trabalhador a realizar dentro do seu conhecimento específico, tornando o trabalho prazeroso, também denominado sofrimento criativo (Dejours, 2015). No entanto, cabe ressaltar que esta autonomia dada ao trabalhador não deve ser fonte de sobrecarga de trabalho e de acúmulo de responsabilidades incompatíveis com o cargo que ocupa.

As estratégias indiretas também foram citadas. As atividades de lazer, terapia e meditação podem servir como descargas de energia pulsional acumuladas, reduzindo o estresse para que se possa lidar com o dia-a-dia do trabalho quando não se consegue ferramentas suficientes para o enfrentamento da causa do problema. A rede de apoio foi considerada pelos servidores como ponto positivo, fortalecendo os laços e melhorando o trabalho em equipe. Deste modo, de acordo com Dejours (2016), é possível haver cooperação entre os trabalhadores quando se estabelece uma relação de confiança, o que é fundamental para organização dos trabalhadores, por meio de estratégias coletivas de defesa frente às adversidades no trabalho. Gaulejac (2007) reforça que é possível encontrar solidariedade entre os trabalhadores para o enfrentamento dos riscos psicossociais, atenuando seus efeitos psicológicos.

A Categoria 4: sugestões de investimentos para o enfrentamento dos riscos psicossociais, reuniu diversas possibilidades de minimização das dificuldades enfrentadas pelos servidores. Levantamento de necessidades de cada setor quanto a investimento em mobiliário, equipamentos e aumento do quadro de pessoal, bem como a oficialização do teletrabalho, denominado home office e as realocações de servidores respeitando sua formação acadêmica e conhecimento técnico foram os principais pontos levantados, conforme observado nas falas, a seguir:

Retirar as divisórias da sala para ampliação. Inserção de novo mobiliário (mesas e cadeiras). Compra de materiais de apoio para execução do trabalho. Manutenção do filtro de água limpo e higienizado. Troca e manutenção da parte elétrica. Consertar o ar-condicionado. Comprar novos equipamentos, softwares, mobiliário e material (S26).

Me deixarem trabalhar em casa, com meus recursos nos horários que não estou em sala de aula sem questionamento porque não existem condições físicas para trabalhar (S198).

Quanto ao teletrabalho, Gaulejac (2007) ressalta o risco de enfraquecimento das relações interpessoais e, consequentemente, da solidariedade e coletividade da equipe, além do aumento da pressão por produtividade e da solidão entre os trabalhadores. O diálogo foi visto como ferramenta para fortalecer o processo decisório da equipe e melhorar a comunicação vertical e inter e intrassetorial. Dejours (2016) reforça a necessidade de diálogo para o confronto de opiniões, estimulando o trabalho vivo e sentimentos positivos, como utilidade, qualificação e reconhecimento.

Precisamos de muito diálogo e real liberdade para expor nossas opiniões. Isso não ocorre de fato em muitos setores. Por vezes as reuniões de equipe são meramente informativas, é assim que sinto acontecer em meu setor $(S 21)$.

Foram sugeridas capacitações, em especial, para gestores, nas questões inerentes ao cargo de gestão, tendo em vista a sua sensibilização quanto aos riscos psicossociais e à administração pública. Dejours (2015) aponta para a necessidade de 
chefias terem conhecimento acerca de todo o processo de trabalho, pois as falhas podem ocorrer por não terem sido previamente planejadas. Foram citadas também capacitações relacionadas ao combate a incêndio e situações de urgência e emergência, fruto do medo pela falta de manutenção predial e de equipamentos, o que, de acordo com Dejours (2015), aumenta a carga psicossensóriomotora pela sensação de insegurança.

\section{Considerações Finais}

Os resultados do presente estudo nos mostram que o trabalhador pode ser um agente modificador de seu ambiente de trabalho, tendo a equipe de saúde do trabalhador como facilitador para as transformações necessárias. A partir dos apontamentos levantados foi possível estabelecer diálogo com os gestores, de modo a sugerir os investimentos necessários para melhoria do ambiente de trabalho e dar retorno aos servidores acerca dos desdobramentos do estudo, além de trabalhar especificamente com grupos de servidores e de gestores, utilizando como metodologia a psicodinâmica do trabalho.

Deste modo, entende-se como necessária que a metodologia estabelecida para análise dos riscos psicossociais no trabalho seja estendida a todas as unidades da instituição, contribuindo de maneira global para ações de promoção de saúde específicas e estabelecimento de nexo causal do adoecimento mental com o trabalho desenvolvido pelo indivíduo. Estimula-se ainda a participação ativa dos servidores na construção de um ambiente de trabalho com menos impacto na saúde dos trabalhadores.

\section{Referências}

Antunes, R.; Praun, L. (2015). A sociedade dos adoecimentos no trabalho. Serviço Social \& Sociedade, (123), 407-427, jul/set, 2015. https://doi.org/10.1590/0101-6628.030.

Association of Business Process Management Professionals. (2013). BPM CBOK. Guia para o gerenciamento de processos de negócio. Brasília: ABPMP Brasil, 2013. 453 p.

Bardin, L. (2010). Análise de conteúdo. 4. ed. Lisboa: Edições 70, 2010.

Dejours, C.; Abdoucheli, E.; Jayet, C. (1994). Psicodinâmica do trabalho: contribuições da escola Dejouriana à análise da relação prazer, sofrimento e trabalho. São Paulo: Atlas, 1994. 145 p.

Dejours, C. (2015). A loucura do trabalho: estudo de psicopatologia do trabalho. São Paulo: Cortez, 2015. 222 p.

Dejours, C. (2016). Organização do trabalho e saúde mental: quais são as responsabilidades do manager? In: MACÊDO, K. B. et al. Organização do trabalho e adoecimento - uma visão interdisciplinar. Goiânia: Ed. da PUC Goiás, 2016. 332 p.

Dul, J.; Weerdmeester, B. (2012). Ergonomia prática. São Paulo: Blucher, 2012. 163 p.

European Agency for Safety and Health At Work. (2014). Cálculo do custo do estresse e dos riscos psicossociais relacionados com o trabalho - uma revisão bibliográfica. Luxemburgo: Publications Office of the European Union, 2014. 46p.

Facas, E. (2013). Protocolo de avaliação dos riscos psicossociais no trabalho - contribuições da psicodinâmica do trabalho. 2013.193 f. Tese (Doutorado em Psicologia Social, do Trabalho e das Organizações) - Instituto de Psicologia, Universidade de Brasília, 2013.

Gaulejac, V. (2007). Gestão como doença social. Aparecida-SP: Ideias \& Letras, 2007. 338 p.

Merlo, A. R. C.; Bottega, C. G.; Perez, K. V. (2015). Atenção ao sofrimento e ao adoecimento psíquico do trabalhador e da trabalhadora: cartilha para profissionais do SUS. Porto Alegre: Evangraf, 2015. 27 p.

Merlo, A. R. C. (2016). Sofrimento psíquico e atenção à Saúde mental. In: Macêdo, K. B. et al. Organização do trabalho e adoecimento - uma visão interdisciplinar. Goiânia: Ed. da PUC Goiás, 2016. 332 p.

Neffa, J. C. (2015). Riesgos psicosociales en el trabajo. Contribuición a su estudio. Ciudad Autónoma de Buenos Aires: Universidad Metropolitana para la Educación y el Trabajo, 2015. 583 p.

Organização Internacional do Trabalho. (1986). Psychosocial factors at work: recognition and control. Genebra: OIT, 1986.88 p.

Pereira, M. S. (2018). Os processos de precarização do trabalho e seus reflexos no adoecimento de trabalhadores brasileiros: um estudo de caso. Revista Interinstitucional de Psicologia, 11(2), 208-220. http://dx.doi.org/10.36298/gerais2019110203.

Rebouças, A. J. A. et al. (1989). Insalubridade: morte lenta no trabalho. São Paulo: Oboré, 1989. 223 p. 
Research, Society and Development, v. 10, n. 7, e57010716901, 2021

(CC BY 4.0) | ISSN 2525-3409 | DOI: http://dx.doi.org/10.33448/rsd-v10i7.16901

Seligmann, E. (2016). Saúde mental relacionada ao trabalho: as visões teóricas sob a pressão da precarização. In: MACÊDO, K. B. et al. Organização do trabalho e adoecimento - uma visão interdisciplinar. Goiânia: Ed. PUC, 2016. 332 p.

Seligmann-Silva, E. (2011). Trabalho e desgaste mental: o direito de ser dono de si mesmo. São Paulo: Cortez, 2011.624 p.

Siegrist, J. (1996). Adverse Health effects of high-effort/low-reward conditions. International Journal of Environmental Research and Public Health, 1(1), 2741. http://dx.doi.org/10.1037/1076-8998.1.1.27.

Slack, N.; Chambers, S.; Johnston, R. (2009). Administração da produção. São Paulo: Atlas, 2009. 703 p. 